PontIFícIA UNIVERSIDADE CATÓLICA dO RIO DE JANEIRO

\title{
A importância do consumo na construção da identidade materna
}

\section{Bruna Ferreira Mondelo}

Trabalho de Conclusão de Curso

CENTRO de CIÊNCIAS SOCIAIS - CCS

DEPARTAMENTO DE ADMINISTRAÇÃO

Graduação em Administração de Empresas 
Bruna Ferreira Mondelo

\section{A importância do consumo na construção da identidade materna}

Trabalho de Conclusão de Curso

Trabalho de Conclusão de Curso, apresentado ao programa de graduação em Administração da PUC-Rio como requisito parcial para a obtenção do título de graduação em Administração.

Orientador(a) : Marina Frid

Rio de Janeiro

Novembro de 2015. 
Todo bem que a mãe goza é bem do filho, espelho que mira afortunada, luz que Ihe põe nos olhos novo brilho! Ser mãe é andar chorando num sorriso! Ser mãe é ter um mundo e não ter nada! Ser mãe é padecer num paraíso! (COELHO NETO, 1920) 


\section{Agradecimentos}

Primeiramente a Deus por me proporcionar o maior bem que podemos ter: a vida.

Aos meus pais pela incansável luta pelo meu aprendizado, pelo apoio e incentivo. Em especial à minha mãe Terezinha, por ter dedicado toda sua vida a $\operatorname{mim}$.

À minha filha Giovana, por me fazer a mãe mais feliz do mundo e por ter inspirado esse trabalho.

À minha orientadora Marina Frid, que acolheu o meu tema com um voto de confiança.

E por fim, ao meu companheiro de noites não dormidas enquanto escrevia meu trabalho, meu filho de quatro patas Apolo. 


\section{Resumo}

Mondelo, Bruna. A importância do consumo na construção da identidade materna. Rio de Janeiro, 2015. 34p. Trabalho de Conclusão de Curso Departamento de Administração. Pontifícia Universidade Católica do Rio de Janeiro.

O presente estudo busca analisar relações entre práticas de consumo e a experiência da maternidade na vida contemporânea. Em especial, a intenção é investigar como as mulheres que acabaram de ter filhos constroem suas identidades maternas através do consumo. Com isso, a partir da análise do papel do consumo na construção da imagem de "mãe" para essas mulheres busca-se entender padrões de consumo que marcam uma transição definitiva da vida feminina: a maternidade. Para alcançarmos as conclusões da pesquisa foi utilizado o método qualitativo que inclui entrevistas em profundidade com cinco mulheres, do Rio de Janeiro, que se tornaram mães nos últimos nove meses.

Palavras- chave

Maternidade; Consumo; Identidade; Feminismo; Compras 


\section{Abstract}

Mondelo, Bruna. The importance of consumption in the construction of maternal identity. Rio de Janeiro, 2015. 34p. Trabalho de Conclusão de Curso - Departamento de Administração. Pontifícia Universidade Católica do Rio de Janeiro.

This study seeks to analyze relationships between consumption practices and the experience of motherhood in the contemporary life. In particular, the proposal is to investigate how women who have just had a baby construct their maternal identity through consumption. According to that, analyzing the characteristic of consumption that creates the "mother's" image for these women, the study seeks to understand consumption models that mark a definitive transition for female life: motherhood. To establish the conclusions of the research, it was used qualitative methods including interviews with five women of Rio de Janeiro, who became mothers in the past nine months.

\section{Key-words}

Motherhood; Consumption; Identity; Feminism; Shopping 


\section{Sumário}

1 O tema e o problema de estudo 1

1.1. Introdução ao tema e ao problema do estudo 1

1.2. Objetivo do estudo 3

1.3. Justificativa e relevância do estudo 3

2 Revisão de literatura 5

2.1. A mulher moderna e seus lugares sociais 5

2.2. Mulheres, mídias e consumos

2.3. O amor e as compras 11

3 Métodos e procedimentos de coleta e de análise de dados do estudo 15

3.1. Metódo de pesquisa utilizado 15

3.2. Seleção de Informantes $\quad 17$

3.3. Coleta de Dados 20

4 Apresentação e análise dos resultados 23

4.1. Sonho versus realidade - O que é ser mãe? 23

4.2. A construção do enxoval 26

4.3. Sobre o comportamento de compras $\quad 27$

4.4. Mudanças proporcionadas pela maternidade 29

4.5. Análise dos resultados 30

5 Conclusões e recomendações para novos estudos 31

6 Referências Bibliográficas 32 


\section{Lista de figuras}

Figura 1 - Campanha da Astra - Comercial de cerveja exclusivamente voltado

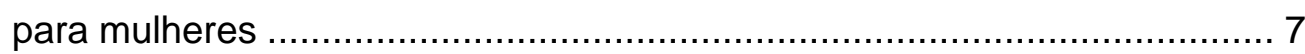

Figura 2 - Campanha da marca Dove - "Real Beleza" lançada em 2004.

Figura 3 - Imagem Site da Disney - Linha Baby 14 


\section{0 tema e o problema de estudo}

\subsection{Introdução ao tema e ao problema do estudo}

O tema escolhido surgiu através da minha atual experiência como recém mãe. Ao longo da gravidez a mulher se transforma e passa a enxergar necessidades que antes lhes eram desconhecidas. Além de alterações físicas e comportamentais geradas pelo contexto da gravidez há também uma alteração do estilo de vida e consequentemente uma modificação nos parâmetros de consumo dessas mulheres. Como sublinha Scavone (2001, p.48):

As transformações pelas quais os padrões de maternidade vêm passando, nos últimos trinta anos, devem ser pensadas em conexão com esses processos sociais e com a integração econômica, a qual contribuiu para acelerar a difusão de novos padrões de comportamento e consumo. Entre estes, podemos citar como exemplo, o consumo crescente das novas tecnologias reprodutivas (contraceptivas e conceptivas) que oferecem às mulheres, da década de sessenta em diante, a possibilidade de escolher com maior segurança a realização da maternidade.

Com o passar dos anos, o modo como as mulheres encaram a maternidade mudou drasticamente. Ser mãe continua gerando os mesmos sentimentos, no entanto o modo como a mulher se apresenta como mãe é vanguardista. Afinal, as mulheres do século XXI já não são mais as mesmas, já não vivem mais na marginalidade da sociedade. Agora atuam como protagonistas da história atual, mais independentes, ocupando papéis fundamentais no mundo em que vivem. As mulheres da atualidade já não se sentem obrigadas a estarem casadas ou terem um relacionamento fixo para engravidar. Muitas, inclusive, recorrem a métodos artificiais para darem à luz de forma independente. Há quem diga que o momento da gravidez proporcione 
uma certa vulnerabilidade nas compras que, somada ao apelo atual da mídia, acaba gerando compras por impulso de maneira quase automática.

Segundo Rocha (2011), uma das maiores características do nosso tempo é que a nossa sociedade é praticamente fundamentada a partir da centralização na comunicação e através das práticas de consumo. A chamada cultura do consumo que nos cerca ultimamente modificou a forma com que as pessoas se relacionam entre si e, mais ainda, a forma como essas pessoas se relacionam com seus bens de consumo. E com as mulheres que acabaram de se tornarem mães não é diferente.

A fim de entendermos melhor essa mudança de identidade materna, precisamos antes de tudo encarar o contexto sociocultural em que estamos inseridos. Segundo Duarte (2007), precisamos compreender o cenário atual socioeconômico do ocidente industrializado, que tem provocado mudanças significativas na vida dos indivíduos, incluindo mudanças nas expectativas do papel da mulher na sociedade.

Outra questão que não pode ser negligenciada é o poder do consumismo feminino que superou a casa dos US\$13 bilhões em 2009. De acordo com Silverstein (2009), a chamada "economia feminista" atingirá um patamar maior que as economias da China e Índia juntas. Segundo Davies et. al. (2010), a maternidade traz uma série de alterações físicas, biológicas e psicológicas, que unidas a apelos externos construídos pelo marketing oferecem impactos na vida desta nova mãe.

Neste trabalho, a relação entre consumo e maternidade será explorada tendo como base certas teorias e conceitos da antropologia do consumo e do comportamento do consumidor que buscam cada vez mais analisar práticas, hábitos e experiências das diversas unidades familiares com o universo de bens. Alguns dos autores de antropologia costumavam associar o trabalho como uma das principais influências na construção da identidade da mulher. Hoje em dia, muitos autores, como por exemplo Ransome (2005), acreditam que o consumo seja um dos principais responsáveis pela construção da identidade das mulheres.

Com isso, o presente trabalho busca examinar o panorama atual enfrentado por mulheres que acabaram de ser mães, ponderando a realidade da sociedade atual, as mudanças causadas pela maternidade, e identificando a importância que a aquisição de bens físicos traz na construção da identidade materna dessas mães. Qual a importância do consumo na construção da identidade materna? 


\subsection{Objetivo do estudo}

O presente estudo tem como objetivo identificar as mudanças no comportamento de consumo de mulheres após se tornarem mães. Isto é, vamos investigar hábitos, gostos e estilos de consumo adquiridos desde o momento do pós-parto, quando um leque abrangente de opções de produtos e serviços se abre para o universo feminino. O trabalho também busca entender os objetivos, preferências e decisões de compras de mulheres que se tornaram mães a pouco tempo. E com esses dados, analisar o quanto o consumo de bens gera impactos na construção da identidade materna individual destas mães.

\subsection{Justificativa e relevância do estudo}

A complexidade do ambiente de consumo feminino poucos meses após o nascimento do primeiro filho gerou uma curiosidade pessoal que surgiu após a experiência da maternidade. A motivação para o presente estudo aumentou após descobrir que, embora existam alguns estudos que ligam o comportamento de mulheres grávidas e no pós-parto a um tipo específico de consumo, chamado consumo materno, nenhum deles tinha como objetivo identificar como esse consumismo materno afetaria a construção da nova identidade assumida pela mulher.

A maior parte dos estudos encontrados que ligam os dois temas: maternidade e consumo, dizem a respeito da vulnerabilidade causada pelo momento único na vida de uma mulher junto ao apelo das mídias por um consumo desenfreado. O estudo antropológico do consumo e o comportamento dos consumidores têm sido amplamente debatidos, principalmente no que tange ao comportamento de compra doméstico. Alguns autores têm se destacado nesse âmbito, tais como McCraken (2012) e Miller (2002), que inclusive inspiraram a construção teórica do presente trabalho. Outro fator relevante para a abordagem do tema é que o nicho de profissionais e serviços para gestantes têm impulsionado o mercado financeiro, conforme apontou reportagem da revista Veja Rio (2015). 
O estudo foi realizado através da união de pesquisas teóricas a cerca do assunto e informações reais coletadas através de entrevistas em profundidade com mulheres que acabaram de assumir o papel de mãe.

Quanto à motivação teórica do trabalho, esta se deu por não haverem estudos que relacionassem o consumo na maternidade e a construção da identidade materna. A presente pesquisa conduz o conhecimento e dissemina as informações nela contidas à sociedade, de forma a se fazer esclarecedora sobre uma perspectiva ainda pouco estudada, mas bastante promissora. 


\section{Revisão de literatura}

O referencial teórico visa unir teorias antropológicas de consumo e do comportamento do consumidor que serviram como embasamento do estudo, além de classificar alguns aspectos relevantes ao tema tais como a construção da identidade a partir do consumo. Primeiramente, é apresentado de uma forma antropológica as mudanças que ocorreram nos últimos anos no gênero feminino. Posteriormente são apresentadas teorias de consumo doméstico, também baseadas em pesquisas antropológicas e do comportamento do consumidor. Por fim, são apresentadas questões que relacionam consumo e identidade.

\subsection{A mulher moderna e seus lugares sociais}

A relevância do papel da mulher na sociedade ocidental atual é estudada por muitos teóricos, que buscam acompanhar mudanças de paradigmas ocorridas ao longo dos séculos. Esses estudiosos se utilizam de fatores históricos para analisarem as transformações sociais ocorridas durante os anos.

O que define ser uma mulher? Segundo Beauvoir (1980) ser mulher vai além do sentido biológico da forma, ser mulher seria na verdade uma construção social, resultante das relações interpessoais dentro do contexto da realidade desta mulher. Neste sentido, ninguém nasceria mulher mas sim se tornaria uma de acordo com as interações no meio em que vive. Por isso, seria leviano criar um rótulo para todas as mulheres, já que a pluralidade neste caso é inevitável, pois há grande variação de culturas, por exemplo.

No entanto, independente do contexto da realidade vivida por elas, algumas situações são unânimes. Há, ainda, nesse aspecto um dado biológico a questão da gravidez. O papel de proteger e educar já é cultural, embora seja atrelado, de certa forma, ao fato biológico. Segundo Garcia (2015), num passado não muito distante as mulheres eram as principais responsáveis por cuidar do lar, exercendo quase sempre um papel submisso em relação ao homem. No mundo Ocidental, desde as sociedades agrícolas antes da era de Cristo a mulher já apresentava esse papel de geradora e de responsável pelo lar, que presava pelo bom cumprimento das atividades domésticas. 
Essa situação só começou a mudar no início do capitalismo, quando algumas fábricas passaram admitir mulheres em suas folhas de ponto por se tratarem de uma mão de obra mais barata, e isso ficava ainda mais visível em tempos de crise.

\begin{abstract}
Com mais acesso à educação formal e à formação profissional, as mulheres vão, no decorrer do século XX, ocupar gradativamente o espaço público, ao mesmo tempo em que mantêm a responsabilidade na criação do(a)s filho(a)s. Neste contexto, ser ou não ser mãe passou a ter uma dimensão reflexiva, a ser uma decisão racional, influenciada por fatores relacionados às condições subjetivas, econômicas e sociais das mulheres e, também, do casal (SCAVONE, 2001, p.174).
\end{abstract}

Desde o final do século XIX quando começa a se estruturar o feminismo, as mulheres buscam reconhecimento e igualdade perante aos homens, e a cada dia que passa essa batalha vem trazendo melhores frutos. Hoje, além de gerarem vidas, as mulheres trabalham, pagam as suas contas, votam e ganham remunerações mais apropriadas.

Ao longo do século XX a mulher deixa de ser apenas coadjuvante e passa a assumir papel de protagonista na sociedade, assumindo altos cargos, virando empresária, diretora de empresa, presidente de países. É claro que esse contexto não mudou do dia para a noite, foram necessários muitos embates e muitas lutas para que as mulheres pudessem deixar de serem consideradas o "sexo frágil". A história é marcada por muitas mulheres que de fato lutaram e, ainda, lutam por esse reconhecimento de equivalência de gêneros.

A quebra do pensamento de fragilidade feminina, foi ocorrendo vagarosamente através de anos de luta. Hoje em dia, as mulheres são taxadas como pessoas que devem cuidar do seu lar, da sua família, dos seus filhos e ainda da sua carreira. No entanto, esta quebra de paradigmas que houve não impediu que muitas mulheres continuassem sendo "donas de seus lares" e mães. "Tendo deixado de ser necessariamente mãe e dona de casa, a mulher pode até decidir ser apenas mãe e dona de casa"(VAITSMAN, 1994, p.174). A única diferença é que agora a mulher tem mais de uma jornada, houve um acúmulo de funções: ela se divide entre o seu lado profissional e pessoal.

Se a carga de trabalho da mulher aumentou com o passar do tempo, em contrapartida, alguns serviços também foram criados para diminuir os impactos da ambiguidade de ser mulher profissional e mãe. Podemos citar, por exemplo, a 
criação de creches públicas e particulares que auxiliam no processo de educação das crianças quando as mães do século XXI retornam às suas carreiras. Certamente ainda há muito a se fazer em busca da igualdade dos sexos. Mas o mais importante é que a cada dia mais um passo é dado nesta luta.

\subsection{Mulheres, mídias e consumos}

Não podemos negar que as mudanças econômicas, culturais e sociais levaram as mulheres a apresentarem um novo papel na sociedade. Uma das grandes consequências dessa inversão de papéis é que hoje as mulheres têm uma grande participação no mercado de consumo. O peso das compras femininas é tão grande que entender e atender o público feminino passou a ser vital para muitas empresas ao redor do mundo. Com a inserção no mercado de trabalho, "além de controlar o orçamento familiar, com mais renda, começa a ter somas vultosas de dinheiro para gastar consigo mesma, criando grandes oportunidades de mercado" (PETTERLE; MALETTA, 2010, p.50).

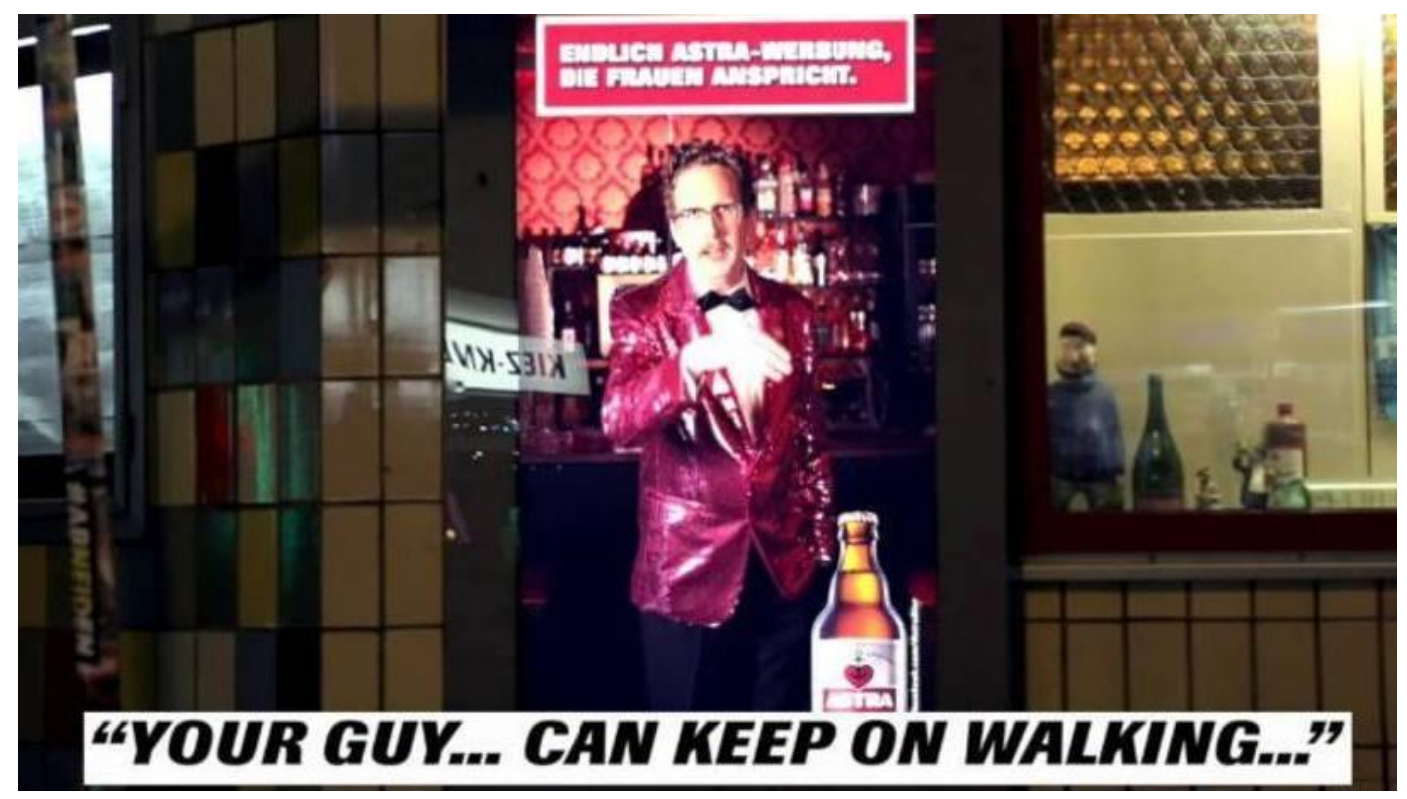

Figura 1 - Campanha da Astra - Comercial de cerveja exclusivamente voltado para mulheres

De acordo com Rocha e Christensen (1999), a diferenciação dos gêneros é algo fundamental para o marketing. É através desta distinção que podem ser feitas ações publicitárias mais pontuais e eficazes, visto que cada gênero se 
relaciona de uma certa maneira com alguns produtos e serviços. No entanto o público feminino só se torna alvo de ações de marketing a partir da década de 1980, quando os profissionais de marketing identificaram um leque de oportunidades de consumo para este grupo social específico. Sendo assim, para que uma campanha publicitária de um determinado artigo possa obter o máximo de efeito, se faz necessário, antes de tudo, o entendimento do público-alvo levando em consideração a realidade vivida pelos consumidores e os desejos destes dentro de seu ambiente social.

Segundo Botton, a diferença de comportamento de compras dos diferentes gêneros fica ainda mais evidente quando falamos em moda e de suas associações. Como sugere Benites (2010, p.28):

Com a falta de tempo para tantas atividades, a mulher sempre procura facilidades e benefícios para ela e sua família. A mulher procura lojas onde seu perfil é compreendido, podendo sentir-se à vontade e desligar-se dos problemas do dia-a-dia para poder comprar. Por isso as lojas que oferecem uma boa condição de atendimento, benefícios, ambiente adequado com luzes, cores, sons, climatização e odor agradável, ganham pontos com a mulher, pois para ela o consumo tem que ser também um momento de entretenimento.

Johnson e Learned (2005) afirmam que em $80 \%$ das vezes, parte das mulheres o poder de influenciar ou decidir uma compra. Segundo as autoras, devemos dar um novo enfoque para alcançar e atender de forma satisfatória o público feminino: deve-se levar em consideração a privilegiada visão feminina "sem cair no clichê de pressupostos antiquados" (BOTTON, 2012, p.49). Essas mulheres consumidoras, que por muitos anos tiveram seus anseios reprimidos, hoje buscam cada vez mais diferenciação.

Essa busca por serviços e produtos personalizados se reflete muitas vezes nas compras de artigos de maternidade. São lembranças de nascimento personalizadas, enxovais com monogramas que os tornam únicos, serviços diferenciados na hora do parto, etc. As mulheres estão a cada dia mais mostrando a sua individualidade na hora das compras.

Ainda segundo as autoras Johnson e Learned (2005), para se elaborar uma campanha assertiva de marketing voltada para mulheres é preciso, em primeiro lugar, reconhecer o domínio das mulheres na tomada de decisão e influência sobre as compras, sendo elas as principais tomadoras de decisões em 
seus domicílios. É preciso saber a diferença de atitude dos diferentes gêneros, em geral as mulheres dispõem de "uma perspectiva da vida em 360 graus e avaliam serviços e produtos em termos de como eles se encaixarão no contexto mais amplo" (JOHNSON; LEARNED, 2005, p. 35).

Mantendo essa linha de pensamento chega-se à conclusão de um estilo de compras feminino, resultante do poder de interatividade das mulheres. Antes mesmo de efetuarem as compras estas já conseguem enxergar de maneira ampla como a interação com o produto ocorrerá. Além disso, conseguem antecipar os benefícios dos produtos/serviços em suas vidas.

É preciso também que os valores culturais e pessoais sejam levados em consideração na hora da segmentação do público feminino, bem como posições e papéis empregados na sociedade. Definir como um grupo de mulheres com o mesmo "estilo" age é de fundamental importância para criar um produto que esteja adequado às suas necessidades, aumentando as chances de sucesso na aceitação.

Deve ser levado em consideração as próprias características que as mulheres carregam, mulheres costumam ser mais afetivas e sentimentais, conseguem até mesmo crias laços com objetos. Tendem a aderir marcas de produtos que lhes tragam uma experiência afetiva mais intensa. "As mulheres são diferentes dos homens. As mulheres percebem o mundo por meio do próprio gênero. É uma questão genética [...] As mulheres não compram marcas: aderem a elas." (POPCORN; MARIGOLD, 2000, p.31)

Mulheres estão conquistando cada vez mais seu espaço no mercado de trabalho. De acordo com uma pesquisa realizada pelo Instituto Brasileiro de Geografia e Estatística ${ }^{1}$, 44\% da população economicamente ativa é composta por mulheres. Atentas ao poder de compras feminino, muitas empresas têm explorado cada vez mais esse mercado potencial, diariamente são encomendadas novas pesquisas a empresas de consultoria que visam o melhor entendimento desde público latente.

${ }^{1}$ Acesso ao site do IBGE. URL: HTTP://www.ibge.gov.br/. Visitado em 20 de Outubro de 2015. 


\title{
AS MULHERES JÁ SÃO UM TERÇO DOS PROFISSIONAIS DAS CORRETORAS DE VALORES
}

\author{
Elas detêm 50,2\% dos cartões de crédito... (Fonte: Itaucard) \\ ...e representam $44 \%$ da população economicamente ativa. (Fonte: OIT) \\ Mas ocupam apenas $15 \%$ dos cargos diretivos nas empresas (Fonte: Lidem)
}

\section{Participação das mulheres na economia²}

Atualmente, as mulheres são responsáveis pela maior parte do mercado consumidor brasileiro; o poder de consumo das mesmas vai muito além do que a remuneração das mesmas, controlam os seus recursos financeiros e também controlam os recursos financeiros da casa. O Brasil possui $010^{\circ}$ mercado feminino mais atuante do mundo. são elas que controlam $66 \%$ do consumo brasileiro. Espera-se no futuro que essa participação no mercado de consumo cresça cada vez mais, visto que a participação da mulher no mercado de trabalho vem crescendo cada dia mais (PETTERLE; MALETTA, 2010).

O livro de Petterle e Marreta (2010) ainda aponta outro fato curioso no mercado de consumo feminino. Apesar de as mulheres dominarem o mercado consumidor, elas ainda se mostram muito insatisfeitas com as ofertas. Isso ocorre porque as empresas não atendem em número e qualidade os desejos e expectativas deste mercado peculiar quando falamos em produtos e serviços customizados. De acordo com a pesquisa, 89\% das mulheres entrevistadas se declararam insatisfeitas ao menos em um segmento, e em média cada uma está desapontada com quatro segmentos distintos de mercado. Essas mulheres que desempenham cada vez mais tarefas desejam que as ofertas acompanhem esse ritmo atendendo de maneira mais eficaz suas reais necessidades. Esses serviços/produtos almejados deveriam ser descomplicados e que de certa forma contribuíssem para abrandar as inquietações burocráticas. Se antes as mulheres lutavam por equidade e liberdade, hoje, ao contrário, elas buscam por produtos/ serviços mais diferenciados de acordo com as suas necessidades específicas.

\footnotetext{
${ }^{2}$ Retirado do site: http://www.terra.com.br/. Acesso em 20 de Outubro de 2015.
} 


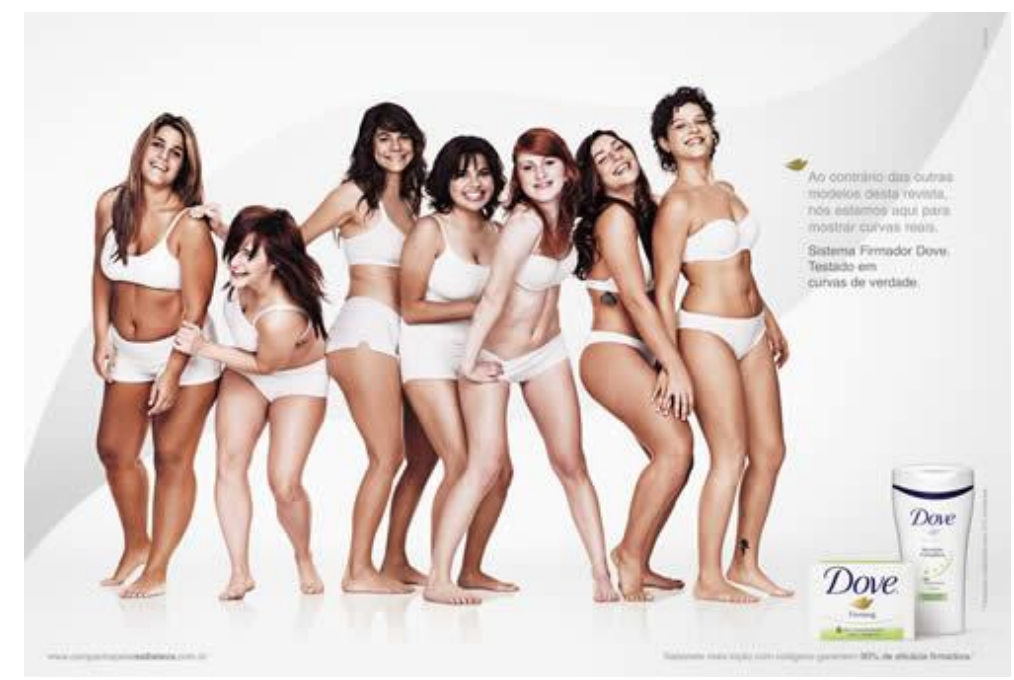

Figura 2 - Campanha da marca Dove - "Real Beleza" lançada em 2004

Na pesquisa de Petterle e Marreta (2010), para melhor estudar o comportamento de consumo das brasileiras os autores criaram dois tipos de consumo levando em consideração a decisão de compra, mas desconsiderando quem pagava pelo produto e/ou serviço: o direto e o de influência. Quando há o consumo direto a própria pessoa tem o poder de decisão de compra, e já quando é de influência há a existência da mulher por traz da escolha de compras feitas em conjunto com homens, que podem ser pai, filhos, marido.

Na média deste agrupamento, as mulheres controlam $83 \%$ do consumo, o que equivale a $\mathrm{R} \$ 524$ bilhões. Juntos estes mercados representam $40 \%$ do que é controlado pelas mulheres no consumo total das famílias. Os números mostram uma responsabilidade feminina no cuidado com os filhos e a preocupação com a aparência. (PETTERLE; MALETTA, 2010, p.25)

\subsection{0 amor e as compras}

Em a "Teoria das Compras", Miller (2002) realizou um estudo etnográfico sobre as atividades de compras de mulheres em um bairro de Londres, e examina as formas pelas quais elas desenvolvem e criam relações sociais através das escolhas e seleções de mercadorias.

De acordo com uma das entrevistadas no livro de Miller (2002), ela se enxerga nas compras o lar com um papel de quem tem que buscar os melhores 
itens que trarão benefícios para sua família, sendo ela responsável por "selecionar mercadorias que se propõem a ser educativas, edificantes, e num sentido vago, moralmente superiores."(MILLER, 2002, p.32) Neste sentido as mulheres teriam nas compras a responsabilidade de encontrar o melhor para a sua família, pensando sempre nos benefícios que este objeto de consumo poderá trazer.

Outro ponto apresentado neste livro é que estas mulheres não se sentem submissas às vontades das outras pessoas, mas, muito pelo contrário, elas se sentem mais capacitadas a comprarem coisas mais adequadas por possuírem uma visão mais ampla do que os outros membros da família precisam. Elas reconhecem as preferências dos familiares, mas não se sentem obrigadas a apenas realizá-las. Pelo contrário, se sentem no direito de persuadi-los a utilizarem o que ela julga ser o melhor para eles. Segundo o autor, para essas donas-de-casa comprar se traduz em um ato de amor. E neste caso a palavra "amor" envolveria diversas variantes, tais como: responsabilidade, carinho, hábito, obrigações e preocupações. O amor se materializa, neste misto onde as compras tem um papel central nas práticas de sensibilidade, cuidado e preocupação familiar.

De acordo com McCracken (2012), os bens de consumo são fundamentais para nossa sociedade. Isso porque neles são depositada significações que empregamos para definir a nós mesmos. Quase sempre atribuímos significados aos nossos pertences utilizando-os para edificar nosso mundo particular e público. Desta forma, os bens de consumo têm participação especial no molde de nossas personalidades. Em nossa sociedade atual, as pessoas são na maior parte das vezes livres para viverem da forma que acham correta, cada vez mais as pessoas optam por comportamentos ligados ao gênero, idade, estilo de vida e classe.

Bens nos ajudam a fazer escolhas. Nos ajudam a tornar nossa cultura concreta e pública (por meio do marketing e varejo). Nos ajudam a selecionar e assumir novos significados (por meio do uso). E nos ajudam a mudar significados (por meio da inovação). Bens nos ajudam a aprender, fazer, expor e mudar as escolhas demandadas por nossa sociedade individualista. Não são prisões, mas instrumentos para a personalidade. (MCCRACKEN, 2012, p.3) 
Vale ressaltar que isso não significa que os bens de consumo sejam livres de qualquer julgamento, prova disso são os estereótipos implícitos em alguns bens. E estes contribuem com a vinculação de determinados objetos a determinados perfis de pessoas, por exemplo: coisas de mulheres, imigrantes, dos mais jovens, dos mais velhos, das mães, etc.

Da mesma forma ocorre o inverso, alguns objetos servem para destruir alguns estereótipos, tais como o modo de se vestir que alguns revolucionários adotam a fim de se verem livres de significados antigos e construírem novos. McCraken (2012) define um antagonismo dos bens e seus significados, já que segundo ele esses podem ser tanto a chave quanto a cela de uma prisão.

Há uma exploração do mito de "ser uma boa mãe" utilizado pela mídia em prol do crescimento do nicho tão promissor que é o da maternidade. Há uma ideologia criada em cima deste mito que acaba influenciando as mães a comprarem determinados produtos e não outros por estes serem, em tese, as melhores opções a proporcionar aos seus filhos, levando-as a serem boas mães. Para tanto, a mídia se utiliza de vários artifícios, entre eles um dos que mais se destacam é a utilização de profissionais geralmente renomados, que são autoridades em suas áreas, e que prestam opiniões a favor de determinados produtos/serviços passando uma credibilidade dos mesmos em favorecer a criança e a mãe. Isto pode ocorrer através de comerciais televisivos, artigos em revistas voltadas para o público materno, sites, livros, etc. As mães tendem a ser mais vulneráveis ao acreditarem que estão fazendo o melhor para seus filhos (DAVIES et al., 2010).

A fim de conquistarem cada vez mais nichos específicos no mercado, as empresas do século XXI passaram a agir de diferentes maneiras de acordo com cada fase vivida pelas mulheres. E não é diferente quando chega a fase da maternidade. É uma oportunidade imperdível para a mídia de consumo persuadir as mulheres neste momento tão único, conforme se observa na figura 4. Como exemplo desta mídia exploratória podemos citar o caso da Disney, que resolveu apostar no nicho e passou a oferecer serviços exclusivos às recentes mães. Serviços que vão desde visitas especiais ao mundo mágico, até uma linha de produtos específica para bebês que incluem diversos itens, entre eles: carrinhos, brinquedos para bebês, alimentação, artigos de decoração personalizados, etc (FRIEDMAN, 2011). 


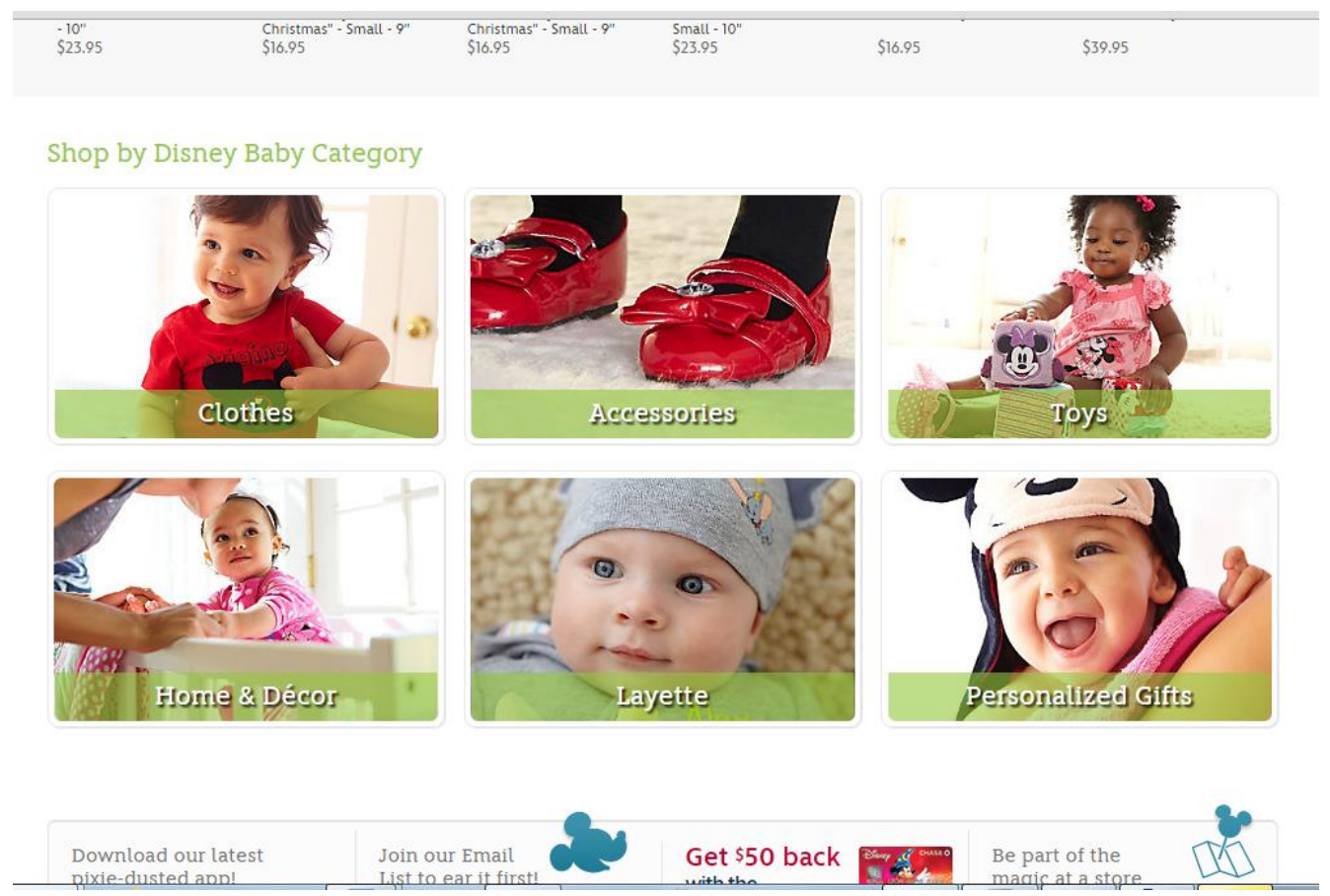

\section{Figura 3 - Imagem Site da disney - Linha Baby ${ }^{3}$}

A questão que colocamos neste caso é se as mães que serão alvo desta ação de marketing irão optar por consumirem esses produtos de uma forma clara e crítica com relação às necessidades que estas possuem, ou se irão comprar por impulso ou falta de controle gerados pelo apelo da mídia associado à vulnerabilidade do momento que estão vivendo.

Segundo Baker et al. (2005), a vulnerabilidade não seria um estado, mas sim uma condição. Sendo assim,embora as mulheres que passam pela experiência da passagem pela maternidade estejam mais disponíveis a experimentar a vulnerabilidade, não significa que todas as pertencentes ao grupo irão apresentar essa característica.

Podemos notar que algumas estratégias de marketing, como, por exemplo, a adotada pela Disney e pelas empresas que se direcionam ao mercado materno, são muito invasivas, influenciando a mulher a deixar o seu racional um pouco de lado e tomar mais atitudes pelo lado emocional e emotivo, aumentando assim a possibilidade de esta assumir um papel de vulnerabilidade.

\footnotetext{
${ }^{3}$ Retirado do site http://www.disneystore.com/
} 


\section{Métodos e procedimentos de coleta e de análise de dados do estudo}

Este capítulo apresenta o método e os procedimentos que foram empregados a fim de alcançar os objetivos que foram propostos, apresentando a forma como ocorrerá a sequência de passos que serão empregados a fim de concluir uma análise e promover uma resposta ao problema de pesquisa que foi proposto.

\subsection{Metódo de pesquisa utilizado}

O presente estudo visa a compreensão de como o consumo se dá numa das fases mais definitivas da vida de uma mulher - a maternidade. Além disso, a intenção é entender de que forma o consumo é capaz de influenciar a construção de uma identidade materna.

Com a intenção de cumprir os objetivos propostos pela pesquisa será utilizado o método qualitativo com entrevistas em profundidade. A metodologia aplicada na construção da pesquisa e no cumprimento das entrevistas foi baseada em um modelo etnográfico com entrevistas em profundidade a fim de estudar as práticas, experiências e comportamentos de consumo de um grupo de mulheres jovens que tiveram seus primeiros filhos recentemente.

A prática etnográfica foi elegida por permitir um olhar mais intenso e cauteloso ao mundo e à realidade pesquisada. A prática etnográfica é considerada indispensável na construção de um entendimento de determinados grupos, já que esta possui em sua essência alguns dos formidáveis conceitos da Antropologia, tais como a aceitação da realidade dos outros e o relativismo cultural.

\footnotetext{
Esse esforço de captar informações em fonte primária, sem intermediações, exige uma certa dose, do que se convencionou chamar em Antropologia, de relativização. Sempre que " (...) o significado de um ato é visto não na sua dimensão absoluta mas no contexto em que acontece: estamos relativizando. Quando compreendemos o outro nos seus próprios valores e
} 
não nos nossos: estamos relativizando." (ROCHA; BARROS; PEREIRA, 2005, p.4)

De acordo com a visão antropológica, relativizar significa interpretar e compreender determinada cultura a partir da visão de seus integrantes. Ou seja, o método etnográfico visa a compreensão de determinado grupo analisado a partir da ótica dos seus integrantes, levando em consideração sua cultura e seus próprios valores. Evitando, por exemplo, que o entrevistador empregue suas visões sobre determinados hábitos e práticas. Desta forma, se comprovada por diversos autores, justifica-se a importância do relativismo cultural em um estudo sobre determinados grupos e sociedades, já que é através do relativismo que nos livramos das amarras das ideias pré-estabelecidas, nos proporcionando assim uma visão mais ampla e clara.

Segundo Rocha, Barros e Pereira (2005), uma das partes mais importantes de um trabalho de campo etnográfico é a execução de entrevistas em profundidade, que são realizadas de forma individual. Nessas entrevistas ocorrem o que chama de escuta ativa que incide na análise verbal e não verbal dos informantes. De acordo com os autores, a linguagem verbal deve ser toda registrada, já que o contato direto com a pessoa que está sendo entrevistada permite detectar o ritmo da conversa, as variações de voz geradas pela emoção, dentre outros aspectos. Já com a linguagem não verbal é possível identificarmos várias informações através dos gestos corporais do entrevistado.

Talvez o aspecto mais relevante da transposição da etnografia para o mundo do Marketing seja, mais que os insights surgidos da utilização da metodologia, a compreensão de que o consumo seja um ato simbólico, cultural e coletivo. Como mostrou Marshall Sahlins em um importante trabalho (1979), a característica própria da vida humana em sociedade é o simbolismo inscrito em todos os atos sociais. Por essa razão, os sentidos da vida humana são construídos coletivamente, não existindo uma realidade objetiva à parte, autônoma em relação aos sujeitos sociais; o consumo, por sua vez, é um dos fenômenos produzidos coletivamente a ser investigado em profundidade, e, cada vez mais, com a aproximação entre as áreas de Antropologia e Marketing. (ROCHA;BARROS;PEREIRA, 2005, p.14) 
Além disso, se fez necessário um levantamento da literatura disponível em estudos anteriores e periódicos nacionais e internacionais, já que o tema não foi muito explorado.Foi utilizada a literatura de forma a estruturar a teoria para um melhor entendimento inicial do tema escolhido e como ponto inicial para a elaboração da pesquisa. Para tanto, foi feita a leitura em diversos artigos publicados em periódicos e livros acadêmicos, permitindo, assim, uma melhor compreensão do tema abordado(MALHOTA, 2001).

\subsection{Seleção de Informantes}

Para analisar a relação entre consumo e maternidade foi selecionado um grupo coeso, com vários atributos em comum para que se pudesse observar suas condutas, valores, crenças e hábitos. O grupo analisado é composto por cinco mulheres jovens com idades entre $22 \mathrm{e}$ 33 anos, de classe média, moradoras da cidade do Rio de Janeiro. Todas possuem vida profissional ativa e são casadas. São mulheres que tiveram seus primeiros filhos a poucos meses e ainda estão experimentando a novidade de ser mãe. Todas possuem uma vida bem agitada, e se dividem entre profissão, relacionamentos sociais e a criação dos filhos.

São mulheres marcadas pela inexperiência com a maternidade, e que ainda estão num processo da construção das suas imagens de mãe.Outra característica geral é que todas são responsáveis pelas compras de casa e pelos artigos do enxoval dos seus filhos.

No grupo, todas revelaram preocupações com os filhos, principalmente com relação ao futuro acadêmico e ao futuro do planeta. Preocupações com a escassez da água apareceram em todos os discursos. A seguir apresento um breve perfil das entrevistadas, e como ocorreu o processo de maternidade das mesmas. A fim de preservar a privacidade das entrevistadas serão fornecidos nomes fictícios.

Márcia possui 28 anos, é formada em publicidade pela Universidade Estácio de Sá, atualmente está fazendo pós-graduação em Marketing Digital, trabalha na área de relacionamento com o cliente de uma grande empresa distribuidora de petróleo. Não planejou a gravidez e, após o susto da notícia resolveu se casar com o pai da sua filha. Está morando no Méier com o marido e a filha em um apartamento alugado. Atualmente, 
sua filha está com oito meses. Divide o seu tempo entre cuidar da filha e da casa, os estudos, trabalhos, mas não abre mão de encontrar com os amigos. Ela e o marido são assalariados e planejam comprar seu imóvel próprio. Relatou que possuía um comportamento de compras quase que compulsivo antes da gravidez, mas que agora, por causa dos gastos com a casa e a nova família, abriu mão de alguns hábitos de consumo exacerbados. Alimentou a filha com leite materno até os cinco meses, quando teve que retornar ao trabalho. Hoje, sua filha fica aos cuidados de sua mãe em dois dias na semana e os outros três dias em uma creche no seu bairro.

Lyvia é carioca, tem 31 anos e mora em Bangu em uma casa própria com o marido e o filho de sete meses. Trabalha como analista de seguros em uma companhia bastante reconhecida no ramo. Lyvia já era casada há 4 anos com seu esposo que também é assalariado. É formada em contabilidade pela UniverCidade e pretende fazer uma especialização quando seu filho estiver um pouco maior. Planejava a gravidez a mais de um ano e, ao dar a luz, realizou o grande sonho de sua vida. Sempre teve um comportamento de compra controlado e permanece assim após a gravidez. Costuma comprar bens para o filho de maneira planejada. Aproveita promoções para estocar os artigos que mais usa, tais como fraldas e lenços umedecidos. Lyvia amamentou até o terceiro mês e, desde então, oferece leite de fórmula artificial para o filho. A fim de não interromper sua vida profissional, Lyvia deixa seu filho todos os dias na casa de sua mãe antes de ir trabalhar e quando regressa do trabalho o leva de volta para casa.

Luciana tem 33 anos, é casada e mora com o marido e a filha de oito meses na Barra da Tijuca. Ela é empreendedora e trabalha em casa na sua própria corretora de seguros. Luciana era casada há dois anos e já programava desde o início do casamento a sua maternidade. Formada em administração pela Universidade Estácio de Sá, atualmente Luciana realiza um especialização no ramo de Seguros. Possuía um nível de controle em seu comportamento de consumo antes da gravidez. Confessa que ainda mantém um certo controle mas que às vezes abre mão dele para proporcionar as melhores experiências para a filha. Luciana não 
conseguiu amamentar, por isso faz uso de fórmulas desde o primeiro mês de vida da sua filha. Ela e o marido trabalham em casa, mas resolveram contratar uma babá para cuidar de sua filha no horário comercial.

Renata tem 22 anos, é casada e mora em apartamento próprio com o seu marido na Tijuca. É formada em publicidade pela PUC, mas confessa que ainda deseja fazer uma segunda graduação em direito. Ela engravidou na lua-de-mel e afirma que sua filha de cinco meses não havia sido planejada. Trabalha como analista na central de marketing de uma grande distribuidora de petróleo. Sempre gastou muito com artigos que não são de primeira necessidade, o que sempre gerou brigas entre ela e o marido. Renata afirma que o comportamento de compras mudou muito após a gravidez e que hoje pensa duas vezes antes de comprar alguma coisa. Também não conseguiu amamentar e por isso faz uso de fórmulas artificiais. Sua filha fica dois dias da semana com uma babá e três dias na semana com sua mãe.

Marla tem 33 anos, é casada há quatro anos e mora em um apartamento próprio em Jardim América. Trabalha em casa, em seu próprio laboratório de próteses dentárias. É formada em administração pela Gama Filho, mas nunca exerceu a profissão. Tem uma filha de nove meses e sua gravidez foi programada. Sempre procurou administrar bem suas finanças e a da casa, mas confessa que tem sofrido muito com os altos gastos com o terceiro membro da família. Marla amamentou até os dois meses de sua filha, mas parou e passou a dar um complemento artificial para a mesma. Atualmente sua filha é cuidada pela avó materna.

Com objetivo de deixar claro a coesão na escolha dos entrevistados foi elaborada a tabela com o perfil do grupo. 


\begin{tabular}{|c|c|c|c|c|}
\hline Nome & Idade & Profissão & $\begin{array}{c}\text { Estado } \\
\text { Civil }\end{array}$ & $\begin{array}{c}\text { Idade do Bebê } \\
\text { (meses) }\end{array}$ \\
\hline Márcia & 28 & $\begin{array}{r}\text { Analista de } \\
\text { Marketing }\end{array}$ & Casada & 8 \\
\hline Lyvia & 31 & $\begin{array}{r}\text { Analista de } \\
\text { Seguros }\end{array}$ & Casada & 7 \\
\hline Luciana & 33 & $\begin{array}{r}\text { Corretora de } \\
\text { Seguros }\end{array}$ & Casada & 8 \\
\hline Renata & 22 & $\begin{array}{r}\text { Analista de } \\
\text { Marketing }\end{array}$ & Casada & 5 \\
\hline Marla & 33 & $\begin{array}{l}\text { Técnica em } \\
\text { Prótese dentária }\end{array}$ & Casada & 9 \\
\hline
\end{tabular}

Conforme podemos analisar, o perfil das entrevistadas é bastante semelhante o que leva ao enquadramento em um único grupo para estudo.

\subsection{Coleta de Dados}

No estudo foi aplicado a metodologia etnográfica onde entrevistas em profundidade foram utilizadas a fim de se compreender de forma mais objetiva e clara os valores, as relações sociais e o comportamento de consumo de uma grupo pequeno de mulheres cariocas que foram mães há menos de um ano. Para serem obtidas informações sobre um grupo diferente, maior e/ ou mais heterogêneo, será necessário a confecção de novas pesquisas mais amplas que possam servir de base comparativa junto ao presente trabalho.

As entrevistas foram conduzidas através de um roteiro formado por perguntas abertas que possibilitava à entrevistada expor, com suas palavras e referencias, de maneira livre suas opiniões e pensamentos a respeito do tema.

O grupo é composto por cinco jovens cariocas que passaram pela experiência de maternidade a pouco tempo, com idades entre 22 e 33 anos, casadas, aqui apelidadas de: Márcia, Lyvia, Luciana, Renata e Marla. O critério de seleção das entrevistadas foi baseado na experiência recente de ser mãe. Apesar de não se relacionarem entre si, todas possuem um perfil bem parecido. 
As entrevistas ocorreram durante o mês de outubro de 2015, individualmente, na residência das entrevistadas.

Abaixo estão listadas algumas perguntas do roteiro utilizado nas entrevistas:

- Idade

- Estado Civil

- Nível de escolaridade

- Profissão

- Bairro em que reside

- Como você se vê como mãe?

- O que é ser uma boa mãe para você?

- Como é a sua relação com o seu filho?

- Quais são as suas expectativas com relação ao futuro do seu filho?

- Como foi amamentar?

- O que pensa sobre o uso de fórmulas infantis?

- Como você montou o enxoval do bebê? Você teve alguma ajuda?

- Você fez o enxoval no Brasil ou no exterior?

- Quais são os critérios adotados na hora da escolha de um item para o seu filho (valor, aparência, qualidade, conforto, segurança, marca)?

- Você tem alguma marca infantil favorita?

- Como era seu comportamento de compras antes da chegada dos filhos? E depois?

- Costuma programar as compras para o bebê?

- Você fez a compra de algum item que depois tenha julgado desnecessário?

- Uma experiência positiva e uma negativa com um produto que tenha mudado a sua vida.

- Como era a sua rotina antes e depois do nascimento do seu filho?

- Teve que fazer adaptações em casa para a chegada do bebê?

- O que não pode faltar na sua casa? 
O questionário semi-estruturado serviu apenas como base, já que em todos os momentos as entrevistadas eram convidadas a falar abertamente sobre os mais diversos assuntos que surgissem. 


\section{Apresentação e análise dos resultados}

O presente capítulo abordará os resultados encontrados na pesquisa a fim de analisar os discursos das mães entrevistadas em relação às experiências vividas por estas após a maternidade. Incluindo suas escolhas e sentimentos, principalmente os ligados ao consumo neste período. E assim, é chegada à conclusão de como o consumo influencia na construção de uma identidade materna.

\subsection{Sonho versus realidade - $O$ que é ser mãe?}

A questão que abria o roteiro foi uma das que mais gerou respostas diferentes, mas que no fundo levavam a mesma lógica. Todas entrevistadas falaram de como a maternidade é diferente do que esperavam e de como a mídia vende um amor incondicional que na verdade não nasce com o bebê, mas sim acontece com a convivência. Conforme fala Renata:

Eu sempre tive na minha cabeça uma visão de que ser mãe era algo extraordinário. Que um amor incondicional simplesmente nascia com o bebê. Mas a realidade é muito diferente do que a gente espera. De repente me vi ali: suja, vulnerável, enfraquecida com o parto e ainda tendo que servir de alimento para uma outra pessoa. Que nem sequer esboça reações e interage. Simplesmente veio uma tristeza profunda quando este amor não ocorreu. Me questionei diversas vezes qual seria o meu problema. Nas novelas e nos filmes esse amor é muito lindo, mas na vida real é bem difícil. Ser mãe é abrir mão de muitas coisas. É muito mais dar que receber no início. Ser mãe é se doar por inteira para uma pessoa que você nunca viu.

Todas relembraram as dificuldades do início da maternidade e como as experiências cotidianas com os bebês ajudaram na construção do vínculo. Hoje todas afirmaram que não se arrependeram nenhum minuto de passar por todas as situações embaraçosas do início da gravidez. Hoje segundo Lyvia: 
É muito bom ser mãe, é muito gostoso. Dá muito trabalho, é muito cansativo, mas eu me sinto tão bem. É tão gratificante. Todo o sacrifício valeu e vale a pena. O que eu posso dizer sobre ser mãe é que pra mim é um privilégio, porque algumas pessoas não tiveram essa oportunidade. Algumas lutam muito para ser e não conseguem. Então me sinto muito privilegiada, ainda mais sendo mãe do meu filho que é uma criança maravilhosa. Pra mim foi muito difícil no início, mas está sendo uma experiência muito boa.

Ainda segundo a Luciana:

Olha eu sempre quis ter um filho, e planejei muito para ter a minha filha. E quando eu recebi a notícia que eu tava grávida parece assim que eu não estava acreditando. Até sentir mexer, você meio que não acredita que tem um bebê ali dentro. Mas a gente vê aquele bebezinho fofinho e a gente acha que é tudo mil maravilhas, né? Mas ninguém conta o que tem por trás de tudo isso. E quando eles nascem a gente descobre como é que é o mundo de mãe. São noites mal dormidas, a gente vive um cansaço mas é um cansaço bom. Por que a gente quer ver eles bem cuidados. Saber que estão alimentados,tranquilos, limpinhos. Então assim, a gente está morta de cansaço, mas vendo que eles estão bem a gente fica feliz. E depois que eu virei mãe também eu comecei a ver o mundo de outra forma. Assim, eu começo a pensar eu vejo, assim, o futuro dela. E ai eu já fico pensando como que vai ser o futuro dela. Aí tento melhorar as coisas. Até mesmo o meu jeito de viver. Por exemplo, vou poupar água porque o futuro dela é passar por dificuldades.

Três das mães, Luciana, Lyvia e Renata demonstraram preocupações quanto ao futuro dos recursos naturais do planeta. E falaram que sempre que podem procuram tomar atitudes que melhorem as condições do planeta.

Todas demonstraram uma ótima relação com os filhos. No entanto deixaram claro o quanto é cansativo ser mãe e todas deixaram claro que são as mães as principais responsáveis pelos seus filhos. De maneira geral, dizem que os pais costumam participar mais em alguns momentos específicos deixando quase todo o trabalho para elas. Segundo Márcia:

O único problema é que o filho é da mãe. Ajudar ele (pai) ajuda, mas não é a mesma coisa não. A responsabilidade cai muito mais em cima de nós mulheres.

Segundo Marla, o relacionamento com a filha não podia ser melhor, Renata também acredita que o relacionamento seja perfeito. 
Todas as mães entrevistadas deixaram claro mais uma vez a preocupação com o futuro do meio ambiente no futuro. Outra questão apontada por todas foi a preocupação com proporcionar bases, principalmente no que tange aos estudos, para que no futuro possam dizer que fizeram tudo pelos seus filhos.

Mas acompanhado com a preocupação com os estudos, veio a preocupação de como bancar eles. Segundo Luciana:

Eu penso que eu quero que ela tenha uma boa educação e infelizmente aonde nós vivemos pra que isso aconteça a gente tem que gastar, e não é pouco é muito. Então desde já eu já começo a pensar quanto custa uma boa escola pra ela. Quanto que isso vai me custar? Eu acho que a base de tudo é a educação. E a primeira coisa que eu posso fazer por ela é matricular ela em uma boa escola. Mas eu sei que isso vai me custar muito. Por isso desde já eu estou me programando financeiramente.

De todas as entrevistadas apenas a Márcia conseguiu um manter apenas o aleitamento materno no início da vida de sua filha. Todas as outras mães tiveram que utilizar o complemento alimentar desde o nascimento da criança, o que gerou uma frustração nas mesmas no início por conta da pressão da sociedade pelo aleitamento materno. Mas todas garantem que essa questão agora já está bem resolvida. Segundo a Marla:

Eu achei que era instantâneo, que o bebê nascesse mamando, mas o problema é que não é assim. E a sociedade não ajuda muito, lembro que toda vez que contava que ela tomava complemento uma enxurrada de críticas caia em mim. $O$ difícil é que as pessoas sempre acham que foi uma opção sua, quando na verdade não é assim. Pra falar a verdade nem me sentia confortável em pagar por algo industrializado que alimentasse a minha filha ao invés de mim. Mas não tive o que fazer.

Nenhuma das entrevistadas demonstrou um impacto no orçamento gerado pelo consumo de leite artificial, segundo Lyvia:

A alimentação é tão fundamental que eu nem ligo de pagar. Pago caro em fraldas que jogo no lixo e então porque não proporcionar a melhor alimentação para o meu garoto. 


\subsection{A construção do enxoval}

Das cinco entrevistadas, três afirmaram que praticamente ganharam todas as coisas do enxoval, e as outras duas que compraram tudo optaram por fazê-lo fora do país. Há uma nítida comparação entre o que elas tiveram na infância e o que elas querem proporcionar para seus filhos.

Duas das entrevistadas tiveram o apoio financeiro e foram influenciadas algumas vezes por opiniões dos maridos, As outras três afirmaram que apenas tiveram o apoio financeiro. Em todos os casos, os maridos se mostraram mais preocupados com os exageros cometidos nas compras e a preocupação financeira com os altos gastos. Segundo Renata:

Meu marido não participava de nada, nem para dar uma opinião sobre qual urso comprar. Mas em compensação no quesito controle ele se superou. Cheguei a chorar em uma feira porque via todo mundo comprando horrores e ele só fazendo contas e achando que tudo que eu queria era desnecessário. Hoje vejo que ele tinha uma certa razão. Tudo o que eu via eu queria, nem me importava com o valor ou utilidade. Achava que eu precisava de toda aquela tralha para ser uma boa mãe.

Sem dúvida nenhuma o critério mais utilizado foi segurança e conforto na hora da escolha dos itens, no entanto todos as outras considerações também foram citadas em menor proporção. Segundo Lyvia:

Segurança é tudo, ele é meu bem maior. E se tiver que pagar mais por isso eu irei pagar, nem suporto a ideia de ter colocado um filho no mundo e não poder proporcionar o melhor para ele.

Foram citadas diversas marcas infantis, variando bastante o segmento. Renata, por exemplo, trouxe logo como melhor marca a Philips Avent. Márcia lembrou de uma loja de artigos infantis online chamada Tricae. Luciana disse que todas as mamadeiras da filha dela são da marca Tommee Tippee. Lyvia respondeu que não vivia sem as coisas da Dr Brown. Já Marla falou que ela tem algumas marcas que gosta, mas que, em geral, as melhores são as mais caras.

Aliás essa é uma visão compartilhada, a maior parte das mães entende que a qualidade está atrelada ao preço do produto, sendo assim quanto mais caros são os produtos melhores estes seriam. Segundo Marla: 
Infelizmente os melhores são os mais caros e meu orçamento já está bem comprometido com os novos gastos que vieram juntos com minha filha.

\subsection{Sobre o comportamento de compras}

A maior parte das entrevistadas disse compravam com regularidade antes de terem filhos, mas a maioria assume também que isso mudou muito depois do primeiro filho. Márcia e Renata relataram que antes de engravidarem tinham um comportamento de compras quase que desenfreado. Gastavam com bens principalmente com os ligados a moda e beleza. Segundo Renata:

Comprava tudo que eu queria, tudo mesmo. Muitas vezes nem poderia estar gastando meu dinheiro com aquilo, mas não tinha jeito. Comprava mesmo. Isso gerava conflitos com a minha mãe na época, que dizia que eu nunca teria responsabilidade com o dinheiro. Tinha tanta roupa no meu armário, algumas ainda com etiqueta.

No entanto as duas afirmaram que o comportamento de compras mudou após a gravidez. A preocupação em manter o conforto e bem-estar de seus filhos influenciou numa mudança radical. Hoje ambas afirmam que já não compram mais com tanto por impulso, que planejam bastante antes de adquirir um item. Pensam muito antes de comprar e evitam comprar bens que não terão grandes utilidades. De acordo com Márcia:

Agora não, estou bem mais controlada. Pesquiso, analiso e comparo antes de comprar. Não só pra oferecer o melhor pra minha filha, mas também para poder proporcionar a melhor coisa de uma forma acessível que não interfira tanto nas minhas finanças. Porque hoje cada mísero centavo faz uma diferença enorme. Pra mim e pra minha família.

Aliás, todas demonstraram bastante planejamento na hora de comprar, raramente adquirem itens sem pesquisar os benefícios e melhores preços. Parte desta mudança de comportamento em da pressão feita pelos maridos.

Todas afirmaram ter comprado ao menos um item que hoje consideram sem utilidade, mas que a culpa também se deu pela falta de experiência. E que em contra partida alguns dos itens mais importantes só foram comprados após 
darem a luz e identificarem na própria rotina a necessidade de tê-los. Como o exemplo de Marla:

Eu achava esterilizador de mamadeiras uma besteira. Imagina, era só ferver as mamadeiras que estariam prontas para uso. O problema é que eu não imaginava que iria deixar sempre mais tempo que o necessário. Várias vezes esqueci o fogo ligado por mais tempo do que deveria. E ai sempre derretia uma coisa ou outra. Até que finalmente entendi que não podia mas viver sem um esterilizador. $E$ foi um dos melhores investimentos que fiz até hoje. [...] Sabe qual é o verdadeiro problema? É que durante meu enxoval inteiro eu tinha a seguinte visão: "não compre nada que a sua mãe não tenha comprado para você". O problema é que o mundo mudou e as nossas necessidades em nada se parecem com as das nossas mães.

Outra aspecto que devemos levar em consideração é a constante comparação entre a maternidade vivida por elas e por suas mães. A maioria possui esse discurso de ter a mãe como um grande espelho influenciador. Assumem que se espelham nas mães para certas coisas. Segundo Lyvia:

Ela é meu grande espelho, sabe? Ela já passou por tudo isso e agora eu estou aqui. Sou mãe, e busco nela respostas que eu não encontro as vezes. De verdade, ela é meu maior exemplo de vida.

De forma quase que contraditória, elas também encontram nas mães a motivação para serem diferentes. Segundo elas, hoje tentam fazer tudo o que suas mães não puderam proporcionar a elas. Segundo Márcia:

O quarto da minha filha foi uma das coisas que mais lutei para fazer da maneira mais perfeita possível. A minha mãe infelizmente nunca pôde me proporcionar isso. O sonho da minha vida era ter um quarto para chamar de meu. Não queria que ela tivesse o mesmo sentimento que eu tenho. Então, investi pesado nesse quesito.

Quando questionadas sobre uma experiência negativa marcante com algum produto, Marla explicitou que se arrependeu do berço comprado que não Ihe proporciona muitas opções. Luciana e Márcia relataram situações em que se sentiram decepcionadas por lojas famosas no ramo de maternidade por terem experimentado problemas com a entrega das compras realizadas. Renata relatou que o carrinho comprado por ela não é muito funcional e que por isso 
acaba ficando de lado. Já Lyvia relatou uma experiência que teve com uma famosa marca de cosméticos para bebê, um sabonete que possui uma embalagem que favorece o desperdício.

Entrei em contato com o SAC na mesma hora. Poxa a embalagem é péssima, definitivamente eles não pensaram na gente. Não devem ter a noção de como é dar um banho em um bebê. Segurar, enxaguar e ainda ter que se virar para pegar o produto.

Quanto às experiências positivas, muitas revelaram que algumas marcas a surpreenderam. Marcas mais baratas mas que proporcionaram benefícios muito além dos esperados.

\subsection{Mudanças proporcionadas pela maternidade}

Todas afirmaram que a vida mudou muito depois da maternidade, em todos os âmbitos da vida. Segundo Luciana:

Eu mudei muito, mas muito mesmo. Mudei tudo. Até a maneira como eu enxergo as coisas é diferente. Mudei todas as formas de relacionamento, com meu marido, meu trabalho, minhas amigas. Grande parte dessas mudanças ocorreu de maneira brusca. Simplesmente eu tive que mudar. Um grande exemplo disso é que antes da neném eu saia muito com os amigos, para jantar e jogar conversa fora. E agora? Conto nos dedos as vezes que sai depois da gravidez. Não tenho mais tempo e nem dinheiro também, tudo isso interfere muito.

Todas elas reportaram essas mudanças bruscas de atitudes, não só com relação às compras, mas também nas suas relações sociais. As mudanças também ocorreram em seus domicílios e a maior parte afirmou ter feito mudanças bruscas em prol da adaptação da casa para a chegada do herdeiro. Luciana, por exemplo teve que dividir o seu escritório com o quarto do bebê. Renata só tinha um quarto em sua casa, e por isso teve que fazer uso de móveis planejados a fim de encontrar a forma mais eficaz de aproveitar cada metro quadrado que possui. Ela, a filha e o marido dividem o mesmo quarto, que em sua metade remete a um quarto infantil, e em sua outra metade um quarto adulto. Márcia chegou a se mudar de apartamento pela falta de espaço.

Além de mudanças físicas nas casas, houve também uma mudança radical na lista de compras de casa. Todas afirmam que as fraldas, lenços umedecidos, 
pomadas para assaduras e latas de leite artificial não podem faltar em suas casas.

\subsection{Análise dos resultados}

Como o objetivo desta pesquisa foi analisar o comportamento de consumo após a vinda do primeiro filho a fim de se identificar a importância do consumo na construção de uma nova identidade da mulher, a identidade materna, foi necessária compreensão das mudanças ocorridas nesta nova fase, bem como as alterações no comportamento de compras. Nas repostas oferecidas pelas cinco mães encontramos características que apareceram na teoria que foi analisada.

Ficou claro, após as entrevistas, que são as mulheres as grandes responsáveis pelas compras de casa e da família, assim como Johnson e Learned (2005) afirmaram. As decisões em geral são tomadas por elas, no entanto há uma participação, principalmente financeira de seus parceiros nestas compras. São elas que decidem o que comprar para os seus filhos, bem como pesquisam os benefícios de determinados produtos e marcas, identificam os melhores lugares para compra, com os preços mais acessíveis.

A imagem de ser uma "boa mãe" está muito ligada a proporcionar os melhores bens aos filhos. Assim como definira McCracken (2012) em seu livro, fica clara a participação dos bens de consumo na definição da nossa própria identidade. Até no que tange à educação das crianças havia uma preocupação com o consumo do melhor. Querem proporcionar tudo de melhor que há no mercado paras os filhos. E muitas vezes esse melhor é associado com o preço do produto/serviço, elas fazem uma ligação entre o ser caro e ser bom. Acreditando que o barato não é o melhor para os seus filhos.

A partir das entrevistas, verifica-se que o consumo é uma forma de expressão de amor para estas mães. Atos de compras são manifestações dos sentimentos amorosos que têm em relação aos filhos. Nesse sentido, o presente trabalho está em linha com o trabalho de Miller (2002). Fazer compras é uma demonstração de carinho e afeto. E é neste sentido que o consumo favorece a construção da identidade materna. É muitas vezes a partir dele que as mulheres se definem como sendo "boas mães".

Uma das maiores preocupações dessas mães está associada a proporcionar tudo que tiveram e o que sempre quiseram ter aos seus filhos. Há quase que uma obrigação de ir além do que foi feito pelos seus pais. 


\section{Conclusões e recomendações para novos estudos}

O presente estudo contribui para investigações sobre a relação entre consumo e maternidade, bem como sua importância na construção da identidade dessas jovens mães de primeira viagem.

Diante dos resultados alcançados com as entrevistas em profundidade, podemos considerar que analisar o comportamento de consumo em uma fase tão singular da vida que é a maternidade é uma experiência extremamente rica. Como o estudo foi realizado com poucas entrevistadas, fica como recomendação um estudo maior no futuro que possa avaliar de maneira mais ampla esse papel do consumo na maternidade. Que poderá abranger uma gama maior de variáveis, como uma pesquisa com mulheres de idades mais variadas e que residem em outros lugares.

Outra sugestão pertinente, é a realização de um novo estudo considerando as mulheres que ainda estão grávidas, a fim de analisar melhor toda a construção da identidade materna e as mudanças nos hábitos de consumo. 


\section{Referências Bibliográficas}

BARRETO, A. Nove meses de consumo: da maternidade à vulnerabilidade.Dissertação de Mestrado em Administração. Universidade Federal da Paraíba. João Pessoa - Paraíba, 2012.

BEAUVOIR, S. O segundo sexo: A experiência vivida. Rio de Janeiro: Editora Nova Fronteira, 1980.

BENITES, Tatiana P. Orquestras Sensoriais: Processos de comunicação no varejo de moda íntima. Dissertação de Mestrado. São Paulo:

Faculdade Cásper Líbero, 2010.

BERALDO, B. Maternidade: um sonho de consumo. In: XXXVIII Congresso Brasileiro de Ciências da Comunicação. Pontifícia Universidade católica do Rio de Janeiro, RJ, 2015.

BOTTON, D. C. Prêt-à-porter, prêt-à-cliquer: um estudo sobre o consumo online de jovens mulheres cariocas. Dissertação de Mestrado. Pontifícia Universidade Católica do Rio de Janeiro, Departamento de Administração, 2012.

DAVIES et. al. Motherhood, Marketization, and Consumer Vulnerability. Journal of Macromarketing. 30(4) 384-397, 2010.

DUARTE F.; GONÇALVES M. M. Negotiating motherhood: a dialogical approach. International Journal for Dialogical Science, v. 2, 2007.

FRIEDMAN D. Disney Kids. http://www.earlyyearsinstitute.org/blog/?p=392. Acesso em 28/02/11.

GARCIA, H. S. (08 de Março de 2015). A mulher no mercado do trabalho: uma luta histórica que merece ser compartilhada. Acesso em 16 de Outubro de 2015, disponível em Empório do Direito: http://www.emporiododireito.com.br

LEVY, B. Identidade, consumo e trabalho após a primeira gestação: um estudo exploratório. Dissertação de Mestrado. Rio de Janeiro, Instituto COOPEAD de Administração, 2010.

MALHOTRA, N. Pesquisa de marketing: uma orientação aplicada. $3^{a}$ edição. Porto Alegre: Boman, 2001.

MCCRACKEN, G. Cultura e consumo: uma explicação teórica da estrutura e do movimento do significado cultural dos bens de consumo. Havard Business School, 2007. 
MCCRACKEN, G. (2012). Cultura e Consumo II: mercados, significados e gerenciamento de marcas. Rio de Janeiro: Mauad.

MILLER, D. (2002). Teoria das compras - O que orienta as escolhas dos consumidores . São Paulo - SP: Nobel.

PESSOA, D.; KNOPLECH, C. Maternidade S/A - Profissionais e serviços para gestantes impulsionam mercado de nicho. Veja Rio, 2015.

PETTERLE, A; MALETTA, B. Poderosas consumidoras: o que quer e pensa a nova mulher brasileira. Rio de Janeiro: Rede de Mulheres, 2010.

POPCORN, F; MARIGOLD, L.. Público-alvo: Mulher - Evolution - 8 verdades do marketing para conquistar a consumidora do futuro. Rio de Janeiro: Campus, 2000.

RANSOME, P. Work, consumption \& culture- Affluence and social change in the twenty-first centur. London: Sage Publications, 2005.

ROCHA, A.; CHRISTENSEN, C. Marketing: Teoria e Prática no Brasil. São Paulo: Atlas, 1999

ROCHA, Everardo; BARROS, Carla; PEREIRA, Claudia. Perspectivas do método etnográfico em marketing: consumo, comunicação e netnografia. In: XXIX Encontro da ANPAD, 2005, Brasília. Anais do XXIX Encontro da ANPAD, 2005.

ROCHA, R. DE M.. "A comunicação é ciencia das convergências: ou como enfrentar, criticamente, a dicotomia teoria/prática." IN: ROCHA, R. e CARRASCOZA, J. (orgs). Consumo midiático e culturas da convergência. São Paulo: Miró Editorial, 2011.

SCAVONE, L. Maternidade: transformações na família e nas relações de gênero. Interface_Comunic, Saúde, Educv, v.5, n.8, p.47-60, 2001.

SILVERSTEIN A. M.; SAYRE C. K. How to Capture Your Share of the World's Largest, Fastest-Growing Market. Women want more. The Boston Consulting Group (BCG),Harper Business, 2009.

SOUZA, D. A., KAZMIERCZARK, M., \& COUTO, R. Mulher e sociedade: Como podemos compreender as mulheres à luz de seus direitos sociais na contemporaneidade?. 2012.

TAKEI, R. Transição para a maternidade em diferentes contextos socioculturais: a experiência de mães brasileiras no Brasil e nos EUA. Pós 
graduação em psicologia. Universidade Federal da Bahia, Instituto de Psicologia, 2013.

VAITSMAN, J. Flexíveis e plurais: identidade, casamento e família em circunstâncias pós modernas. Rio de Janeiro: Editora Rocco, 1994. 